\title{
GAME ACTION EFFICIENCY ON VOLLEYBALL GAME STRUCTURES ACCORDING TO THE OPPONENTS' LEVEL
}

\author{
Nicolae-Lucian VOINEA ${ }^{1 *}$, Gloria RAȚ $\breve{A}^{1}$, Alexandru-Rareș PUNI ${ }^{2}$ \\ 1 "Vasile Alecsandri" University, Faculty of Movement, Sport and Health Sciences, Bacău, Romania \\ 2 "Alexandru Ioan Cuza" University, Faculty of Physical Education and Sport, Iași, Romania \\ *Corresponding author: voineanicolaelucian@yahoo.com
}

DOI: https://doi.org/10.51267/icpesk2020bp17

\begin{abstract}
Performance volleyball is composed of two fundamental game structures, namely: structure I (at own service), which includes as game actions the service, block, dig, pass and attack, and structure II (at service reception), which is made up of game actions from service, pass, attack, block and dig. This study highlights the differences between the efficiency indices of game actions on game structures at the Știința Bacău team depending on the opponents' level. This is based on analysing the performance of the teams during the Romanian National Women's Volleyball Championship, 1st Division, which consisted of 18 games, out of which 10 games with level 1 teams and 8 games with level 2 teams. The research hypothesis aimed at verifying the dependence of the efficiency indices of game actions on game structures according to the opponents' level. The subjects of this study were the players of the Știința Bacău team in the 2017-2018 season. As a result of this study, we have found that there are statistically significant differences between the efficiency indices of game actions on game structures according to the opponents' level for service $(p=0.047)$ and dig $(p=0.006)$ in structure I and for attack $(p=$ 0.015 ) in structure II, which confirms the hypothesis of our research.
\end{abstract}

Keywords: efficiency, game actions, opponent, game structures, volleyball.

\section{Introduction}

Volleyball is an interactive game that is divided into two structures, the attack and defence, comprising three or four chained game actions following one another in a hierarchical order (Eom \& Schutz, 1992). Training volleyball teams to achieve performance at the highest level is a rather complex process that depends on the technical, tactical and physical interactions of the available players (Marcelino et al., 2012), instructions that can be found as models in the teaching design. The effectiveness of model-based training depends on the included components. The diversity of conditions and factors that are integrated in the training models excludes the possibility of generalising a hypothetical model with prospective value. Hypothetically determining the quantitative value of a training model is a necessity and takes into account the satisfaction of efficiency conditions represented by: establishing the optimal percentage of components (training factors) of the model corresponding to the players and team games; establishing the motor and functional potential and integrating it into the performance objectives; establishing the relationship between training and competition, general and specific, systemic and structural, functional and structural aspects, and more.

A volleyball match consists of different game actions specific to technical actions, which are service, pass, attack, block and dig, and the success of these executions depends on the skills of the players performing them (Quiroga et al., 2010).

The creation of training models but especially putting them into practice is done through specific operations that indicate the nature of means and implicitly the choice of exercises, but 
also solving precise tasks related to the selection of team players, etc. The development of models must be optimised through different operational schemes that include the following aspects: practising the action in light conditions; practising the action with an emphasis on strengthening the dominant aspect; repeating the action in conditions similar to the game; practising the overall action with an emphasis on automating the dominant physical, technical and tactical aspects; practising the action according to the requirements of dominant motor skills; practising a set of actions with an emphasis on consistency and effectiveness; practising the action in game conditions but also with additional, excessive demands. Modelling the training process represents the materialisation of the coach's mental activity, i.e. the concept of training a team/an athlete according to a model in order to carry out the training process with the highest efficiency. The model contains all the information necessary for an action corresponding to the level of training, in close connection with the training and performance objectives. Regarding performance sport, the efficiency of the training process is materialised in the sports performance achieved in competitions. In volleyball, as in all sports competitions, coaches develop competitive models. The competition/game model, which is considered as a simplified system or a set of essential morphological, physiological, motor, technical, tactical and psychological values constantly highlighted by the demands of a series of competitions and manifested as a unit, ensures the athlete's success materialised in a record, title, victory or priority in the national or international ranking. (Nicu, 2002)

The structure of the game model groups game actions, game phases, fundamental game situations, sets and games structured to face a competition, to earn points or places, but their efficiency also depends on the value, conception and strategy of the opposing team. In volleyball, the efficiency of both the training process and the competition depends on the possibility and ability to analyse the matches. Some published studies were sometimes supported only by theoretical reviews rather than statistical methods aimed to analyse and interpret the results (Silva, Marcelino, Lacerda, \& João, 2016).

Victory or defeat depends on several factors: one of them can be the efficiency of actions in different game structures, when the team is in structure I (service, block, pass and attack) and structure II (pass, attack, block and dig) (Palao et al., 2004; Rabaz et al., 2013; Silva, Sattler, Lacerda, \& João, 2016; Valladares et al., 2016). Another factor in the analysis of victory or defeat is the use of modern statistical methods for processing data obtained in team games, and their interpretation can be very helpful in improving the quality of game action analysis (Sampaio et al., 2004).

The maximum performance of a team can be obtained only if the team controls very well the actions that make up the two game structures. Interrupting the chaining actions, trying to make the opponent wrong (Palao et al., 2004) and believing that the team making the fewest mistakes is most likely close to victory (Silva et al., 2014) are ideas that help to win.

Structure II is more predictable because it depends very much on a single direct action of the opposing team (service); on the other hand, structure I follows an attack of the opposing team and is more unpredictable because it depends on the tactical choice of the opposing setter (Castro et al., 2011).

In structure I of the game, the block is the first line of defence of a team and aims to intercept the opponent's offensive actions (Selinger \& Ackermann-Blount, 1986). The main objective 
of the defence is to control the ball attacked by the opponent to send it to the setter who can initiate the counterattack (Stone, 2002).

It is known that, in structure II, a very good reception creates better conditions for attack and improves the possibility of gaining a point, which stimulates the use of fast attacks (De Conti Teixeira Costa et al., 2014).

The existence of limited information about the efficiency of game actions on game structures according to the opponents' level makes us emphasise the difference between the efficiency indicators of game actions on game structures according to the opponent's level and own team's level.

The aim of our study is to show that there are differences in the two game structures between the efficiency of game actions depending on the level of the opposing teams.

\section{Methodology}

\section{Subjects and place of research}

The subjects of this study were the players of the Știința Bacău team in the 2017-2018 season, for which we analysed the performance of both the players and team in the Romanian National Women's Volleyball Championship - Division A1, in a number of 18 games, out of which 10 games with level 1 teams and 8 games with level 2 teams. The research took place mainly in the Sports Hall in Bacău, but also in the halls from other cities where the teams participating in the 2017-2018 edition of the championship held their official matches.

\section{Purpose of research}

The research aims to perform an analysis of the performance of volleyball players and to highlight the efficiency of the service and the efficiency of dig according to the level of the opponent. In order to achieve this goal, we set two objectives, namely: recording matches using the Data Volley 2007 program (license of the Știința Bacău team); statistical analysis of the results recorded using the IBM SPSS Statistics 20.0 program and the One-Way ANOVA test.

\section{Research methods}

The research methods used in this study were as follows: the bibliographic study method, the data recording and processing method, the statistical method and the graphical method.

\section{Research hypothesis}

The research hypothesis aimed at verifying the dependence of the efficiency indices of game actions on game structures according to the opponents' level. 


\section{Assessment protocol}

The Data Volley 2007 program (license of the Știința Bacău team) was used to record the 18 analysed games of the Știința Bacău team with the teams in the Romanian National Women's Volleyball Championship - Division A1, in the 2017-2018 season.

The efficiency indices were calculated with the help of some formulas that are presented below (Voinea \& Raţă, 2019; Voinea et al., 2018):

The following formula was used to calculate the efficiency of the service game action:

$$
E=\frac{A+B * 0.8+C * 0.6+D * 0.4+E * 0.2}{A+B+C+D+E+F} \text {, where: }
$$

A - represents the service point, scoring 5 points, whose value is 1 ; $\mathrm{B}$ - represents a halfservice of 4 points, whose value is $0.80 ; \mathrm{C}$ - represents a positive service of 3 points, whose value is 0.60 ; D - represents a neutral service of 2 points, whose value is 0.40 ; $\mathrm{E}$ - represents a negative service of 1 point, whose value is $0.20 ; \mathrm{F}$ - represents a service error of 0 points, which has no value.

The following formula was used to calculate the efficiency of pass and dig game actions:

$$
E=\frac{A+B * 0.8+C * 0.6+D * 0.4+E * 0.2}{A+B+C+D+E+F} \text {, where: }
$$

A - represents a perfectly played action of 5 points - whose value is 1 ; B - represents positively played actions of 4 points - whose value is 0.80 ; $\mathrm{C}$ - represents neutrally played actions of 3 points - whose value is 0.60 ; $\mathrm{D}$ - represents negatively played actions of 2 points whose value is 0.40 ; $\mathrm{E}$ - represents half-error played actions of 1 point - whose value is 0.20 ; $\mathrm{F}$ - represents lost actions of 0 points - having no value.

The following formula was used to calculate the efficiency of attack and block game actions:

$$
E=\frac{A+B * 0.75+C * 0.5+D * 0.25}{A+B+C+D+E}, \text { where: }
$$

$\mathrm{A}$ - represents a completed winning action of 4 points - whose value is 1 ; B - represents positively played actions of 3 points - whose value is 0.75 ; C - represents neutrally played actions of 2 points - whose value is 0.50 ; D - represents negatively played actions of 1 point whose value is 0.25 ; $\mathrm{E}$ - represents lost actions of 0 points - having no value.

In order to analyse the efficiency of game actions depending on the opponent's level, we divided the teams into two categories according to the place occupied in the previous season, level 1 (places 1-6) and level 2 (places 7-10).

Statistical analysis of the recorded results was performed using the IBM SPSS Statistics 20.0 program, and we used the One-Way ANOVA test with a significance level of $p=0.05$.

\section{Results}

We present below the analysis of the results achieved in the two fundamental game structures by the Știința Bacău team depending on the opponent's level in the 2017-2018 season, in the 18 matches recorded with the Data Volleyball 2007 program.

Analysing Table 1, we notice that the following results are obtained for service in structure $\mathrm{I}:$

- with level 1 teams, an average of .405 , with a standard deviation of .023 , an average standard error of .007 , a minimum value of .380 and a maximum value of .455 ; 
- with level 2 teams, an average of .442 , with a standard deviation of .047 , an average standard error of .016, a minimum value of .392 and a maximum value of .537;

- a total average of .422 per set, with a standard deviation of .040, an average standard error of .009, a minimum value of .380 and a maximum value of .537 .

Table 1 shows that the attack in structure I has the following results:

- with level 1 teams, an average of .564, with a standard deviation of .070 , an average standard error of .022, a minimum value of .420 and a maximum value of .661 ;

- with level 2 teams, an average of .590 , with a standard deviation of .032 , an average standard error of .011, a minimum value of .527 and a maximum value of .643;

- a total average of .575 per set, with a standard deviation of .057 , an average standard error of .013, a minimum value of .420 and a maximum value of .661 .

Regarding the block in Table 1, we can specify the following results in structure I:

- with level 1 teams, an average of .459 , with a standard deviation of .116, an average standard error of .036, a minimum value of .326 and a maximum value of .663;

- with level 2 teams, an average of .490 , with a standard deviation of .097 , an average standard error of .034, a minimum value of .357 and a maximum value of .596;

- a total average of .473 per set, with a standard deviation of .106, an average standard error of .025 , a minimum value of .326 and a maximum value of .663 .

The dig action in structure I has the following results presented in Table 1:

- with level 1 teams, an average of .393, with a standard deviation of .056, an average standard error of .018, a minimum value of .291 and a maximum value of .471;

- with level 2 teams, an average of .494 , with a standard deviation of .079 , an average standard error of .028, a minimum value of .406 and a maximum value of .624;

- a total average of .438 per set, with a standard deviation of .083 , an average standard error of .019, a minimum value of .291 and a maximum value of .624.

Table 1. Results of the game actions according to the opponent's level in structure I

\begin{tabular}{|c|c|c|c|c|c|c|c|c|c|}
\hline \multicolumn{10}{|c|}{ Descriptive statistics } \\
\hline & & \multirow{2}{*}{$\mathrm{N}$} & \multirow{2}{*}{ Mean } & \multirow{2}{*}{$\begin{array}{c}\text { Std. } \\
\text { Deviation }\end{array}$} & \multirow{2}{*}{$\begin{array}{l}\text { Std. } \\
\text { Error }\end{array}$} & \multicolumn{2}{|c|}{$\begin{array}{l}95 \% \text { Confidence } \\
\text { Interval for Mean }\end{array}$} & \multirow{2}{*}{ Min } & \multirow{2}{*}{$\operatorname{Max}$} \\
\hline & & & & & & $\begin{array}{l}\text { Lower } \\
\text { Bound }\end{array}$ & $\begin{array}{l}\text { Upper } \\
\text { Bound } \\
\end{array}$ & & \\
\hline \multirow{3}{*}{ Service } & Level 1 & 10 & .40550 & .023642 & .007476 & .38859 & .42241 & .380 & .455 \\
\hline & Level 2 & 8 & .44263 & .047955 & .016955 & .40253 & .48272 & .392 & .537 \\
\hline & Total & 18 & .42200 & .040040 & .009437 & .40209 & .44191 & .380 & .537 \\
\hline \multirow{3}{*}{ Attack } & Level 1 & 10 & .56420 & .070916 & .022426 & .51347 & .61493 & .420 & .661 \\
\hline & Level 2 & 8 & .59063 & .032196 & .011383 & .56371 & .61754 & .527 & .643 \\
\hline & Total & 18 & .57594 & .057200 & .013482 & .54750 & 60439 & .420 & .661 \\
\hline \multirow{3}{*}{ Block } & Level 1 & 10 & .45960 & .116744 & .036918 & .37609 & .54311 & .326 & .663 \\
\hline & Level 2 & 8 & .49025 & .097965 & .034636 & .40835 & .57215 & .357 & .596 \\
\hline & Total & 18 & .47322 & .106831 & .025180 & .42010 & .52635 & .326 & .663 \\
\hline \multirow{3}{*}{ Dig } & Level 1 & 10 & .39370 & .056958 & .018012 & .35295 & .43445 & .291 & .471 \\
\hline & Level 2 & 8 & .49488 & .079863 & .028236 & .42811 & .56164 & .406 & .624 \\
\hline & Total & 18 & .43867 & .083785 & .019748 & .39700 & .48033 & .291 & .624 \\
\hline
\end{tabular}

In structure I (from Table 1), it is observed that, on average per set, the attack has the highest efficiency (.575), followed by block (.473), $\mathrm{dig}(.438)$ and service (.422). 
In matches with level 1 teams, it is observed that the game action with the highest average efficiency per set is the attack (.564), followed by block (.459), service (.405) and dig (.393).

In matches with level 2 teams, the highest efficiency of game actions per set is achieved in attack (.590), followed by the pass (.494), block (.490) and service (.442).

In structure I, the highest efficiency indices of game actions were obtained in matches with level 2 teams for service (.422), attack (.590), block (.490) and dig (.494), and the lowest efficiency in matches with level 1 teams for service (.405), attack (.564), block (.459) and dig (.393).

From Table 2, it is observed that there are statistically significant differences between the set averages of the efficiency of game actions depending on the opponent's level in the game structure I for service and pass, but not for attack and block, the other elements that make up this game structure.

Table 2. Results of the One-Way ANOVA test according to the opponent's level in structure I

\begin{tabular}{llccccc}
\hline & & \multicolumn{3}{c}{ ANOVA } & & \\
& & Sum of Squares & Df & Mean Square & F & Sig \\
\hline \multirow{4}{*}{ Service } & Between Groups & .006 & 1 & .006 & 4.639 & .047 \\
& Within Groups & .021 & 16 & .001 & & \\
& Total & .027 & 17 & & & \\
& Between Groups & .003 & 1 & .003 & .946 & .345 \\
Attack & Within Groups & .053 & 16 & .003 & & \\
& Total & .056 & 17 & & & \\
& Between Groups & .004 & 1 & .004 & .352 & .561 \\
Block & Within Groups & .190 & 16 & .012 & & \\
& Total & .194 & 17 & & & \\
& Between Groups & .045 & 1 & .045 & 9.857 & .006 \\
& Within Groups & .074 & 16 & .005 & & \\
\hline
\end{tabular}

Analysing the results presented in Table 2 for the mean differences between the two levels of the efficiency of game actions, we can state that no statistically significant differences are observed between the means of the two levels for the efficiency of the attack $(\mathrm{F}=.946, \mathrm{p}=$ $.345>.05)$ and block $(\mathrm{F}=.352, \mathrm{p}=.561>.05)$.

For service, the One-Way ANOVA test reveals a significant difference between the means of the two levels in structure I for the efficiency indices $(F=4.639, p=.047<0.05)$. 
Table 3. Results of the game actions according to the opponent's level in structure II

\begin{tabular}{|c|c|c|c|c|c|c|c|c|c|}
\hline \multicolumn{10}{|c|}{ Descriptive statistics } \\
\hline & & \multirow{2}{*}{$\mathrm{N}$} & \multirow{2}{*}{ Mean } & \multirow{2}{*}{$\begin{array}{c}\text { Std. } \\
\text { Deviation }\end{array}$} & \multirow{2}{*}{$\begin{array}{l}\text { Std. } \\
\text { Error }\end{array}$} & \multicolumn{2}{|c|}{$\begin{array}{l}95 \% \text { Confidence } \\
\text { Interval for Mean }\end{array}$} & \multirow{2}{*}{ Min } & \multirow{2}{*}{ Max } \\
\hline & & & & & & $\begin{array}{l}\text { Lower } \\
\text { Bound }\end{array}$ & $\begin{array}{l}\text { Upper } \\
\text { Bound }\end{array}$ & & \\
\hline \multirow{4}{*}{ Reception } & Level 1 & 10 & .61790 & .046066 & .014567 & .58495 & .65085 & .530 & .698 \\
\hline & Level 2 & 8 & .59912 & .038595 & .013645 & .56686 & .63139 & .560 & .686 \\
\hline & Total & 18 & .60956 & .042766 & .010080 & .58829 & .63082 & .530 & .698 \\
\hline & Level 1 & 10 & .58100 & .071542 & .022623 & .52982 & .63218 & .482 & .689 \\
\hline \multirow[t]{3}{*}{ Attack } & Level 2 & 8 & .66700 & .060014 & .021218 & .61683 & .71717 & .548 & .732 \\
\hline & Total & 18 & .61922 & .078271 & .018449 & .58030 & .65815 & .482 & .732 \\
\hline & Level 1 & 10 & .52480 & .072982 & .023079 & .47259 & .57701 & .375 & .625 \\
\hline \multirow[t]{3}{*}{ Block } & Level 2 & 8 & .50850 & .256632 & .090733 & .29395 & .72305 & .063 & .857 \\
\hline & Total & 18 & .51756 & .173229 & .040830 & .43141 & .60370 & .063 & .857 \\
\hline & Level 1 & 10 & .41600 & .121450 & 038406 & .32912 & .50288 & .267 & .633 \\
\hline \multirow[t]{2}{*}{ Dig } & Level 2 & 8 & .45413 & 107522 & 038015 & .36423 & .54402 & .267 & .600 \\
\hline & Total & 18 & .43294 & .113795 & .026822 & .37636 & .48953 & .267 & .633 \\
\hline
\end{tabular}

Analysing Table 3, we notice that, in structure II, the following results are obtained for reception:

- with level 1 teams, an average of .617 , with a standard deviation of .046 , an average standard error of .014, a minimum value of .530 and a maximum value of .698;

- with level 2 teams, an average of .599 , with a standard deviation of .038 , an average standard error of .013, a minimum value of .560 and a maximum value of .686 ;

- a total average of .609 per set, with a standard deviation of .042, an average standard error of .010, a minimum value of .530 and a maximum value of .698 .

From Table 3, we notice that the attack action in structure II has the following results:

- with level 1 teams, an average of .581 , with a standard deviation of .071 , an average standard error of .022, a minimum value of .482 and a maximum value of .689;

- with level 2 teams, an average of .667 , with a standard deviation of .060 , an average standard error of .021, a minimum value of .548 and a maximum value of .732;

- a total average of .619 per set, with a standard deviation of .078, an average standard error of .018, a minimum value of .482 and a maximum value of .732 .

Regarding the block action in Table 3, we can specify the following results in structure II:

- with level 1 teams, an average of .524, with a standard deviation of .072, an average standard error of .023, a minimum value of .375 and a maximum value of .625 ;

- with level 2 teams, an average of .508 , with a standard deviation of .256 , an average standard error of .090, a minimum value of .063 and a maximum value of .857 ;

- a total average of .517 per set, with a standard deviation of .173, an average standard error of .040, a minimum value of .063 and a maximum value of .857 .

The dig in structure II has the following results presented in Table 3:

- with level 1 teams, an average of .416, with a standard deviation of .121, an average standard error of .038, a minimum value of .267 and a maximum value of .633;

- with level 2 teams, an average of .454, with a standard deviation of .107, an average standard error of .038, a minimum value of .267 and a maximum value of .600 ; 
- a total average of .432 per set, with a standard deviation of .113, an average standard error of .026, a minimum value of .267 and a maximum value of .633.

According to Table 3, it is observed that, on average per set, the attack has the highest efficiency (.619), followed by reception (.609), block (.517) and dig (.432).

In matches with level 1 teams, it is observed that the game action with the highest average efficiency per set is reception (.617), followed by attack (.581), block (.524) and dig (.416).

In matches with level 2 teams, the highest efficiency of game actions per set was achieved in attack (.667), followed by reception (.599), block (.508) and dig (.454).

From Table 3, it is observed that, on average per set, the attack has the highest efficiency (.619), followed by the pass (.609), block (.517) and dig (.432).

In matches with level 1 teams, it is observed that the game action with the highest average efficiency per set is the pass (.617), followed by attack (.581), block (.524) and dig (.518).

In matches with level 2 teams, the highest efficiency of game actions per set was achieved in attack (.667), followed by the pass (.599), block (.508) and service (.454).

In structure II, the highest efficiency indices of game actions were obtained in matches with level 2 teams for attack (.667) and dig (.454) and in matches with level 1 teams for reception (.617) and block (.524), and the lowest efficiency, in level 2 team matches for reception (.599) and block (.508) and in level 1 team matches for attack (.581) and dig (.416).

Analysing Table 4, we notice that there are statistically significant differences between the averages per set for the efficiency of game actions depending on the opponent's level in the game structure II for attack, but not for reception, block and dig.

Table 4. ANOVA One-Way test results according to the opponent's level in structure II

\begin{tabular}{llccccc}
\hline & & \multicolumn{2}{c}{ ANOVA } & & & \\
& & Sum of Squares & df & Mean Square & F & Sig \\
\hline \multirow{3}{*}{ Service } & Between Groups & .002 & 1 & .002 & .849 & .371 \\
& Within Groups & .030 & 16 & .002 & & \\
& Total & .031 & 17 & & & \\
& Between Groups & .033 & 1 & .033 & 7.379 & .015 \\
Attack & Within Groups & .071 & 16 & .004 & & \\
& Total & .104 & 17 & & & .850 \\
& Between Groups & .001 & 1 & .001 & .037 & \\
& Within Groups & .509 & 16 & .032 & & .497 \\
& Total & .510 & 17 & & .484 & \\
& Between Groups & .006 & 1 & .006 & & \\
& Within Groups & .214 & 16 & .013 & & \\
\hline
\end{tabular}

Thus, an $\mathrm{F}=.849$ and a $\mathrm{p}=.371>.05$ were obtained for passing; for blocking, an $\mathrm{F}=.037$ and a $\mathrm{p}=.850>.05$, and for digging, an $\mathrm{F}=.484$ and a $\mathrm{p}=.497>.05$. These results show that there are no significant differences in the efficiency of game actions that make up the structure II of the game depending on the level of the opponent.

In the game structure II, statistically significant results were obtained in the ANOVA test for the efficiency of the attack $(F=7.379, p=.015<.05)$ depending on the level of the opposing teams. 


\section{Conclusion}

Following this study, we can draw the following conclusions:

- In structure I of the game, significant results were obtained for the efficiency of the service $(\mathrm{p}=.047<.05)$ and the efficiency of $\operatorname{dig}(\mathrm{p}=.006<.01)$ depending on the opponent's level.

- In structure II of the game, significant results were obtained for the efficiency of the attack $(\mathrm{p}=.015<.05)$ depending on the opponent's level.

- No significant results were obtained for the efficiency of the attack $(\mathrm{p}=.345>.05)$ and block $(\mathrm{p}=.561>.05)$ in structure I of the game and for the efficiency of pass $(\mathrm{p}=.371>.05)$, block $(\mathrm{p}=.850>.05)$ and $\operatorname{dig}(\mathrm{p}=.497>.05)$ in structure II of the game depending on the level of the opposing team.

- The hypothesis according to which there are differences between the efficiency indices of game actions on game structures according to the level of the opposing teams is confirmed.

\section{References}

Castro, J., Souza, A., \& Mesquita, I. (2011). Attack efficacy in volleyball: Elite male teams. Perceptual and Motor Skills, 113(2), 395-408. https://doi.org/10.2466/05.25.pms.113.5.395-408

Ciemiński, K. (2018). The efficiency of executing technical actions in volleyball and the teams' gender and sports level. Trends in Sport Science, 3(25), 159-165. https://doi.org/10.29359/bjhpa.09.3.04

De Conti Teixeira Costa, G., Afonso, J., Vieira Barbosa, R., Coutinho, P., \& Mesquita, I. (2014). Predictors of attack efficacy and attack type in high-level Brazilian women's volleyball. Kinesiology: International Journal of Fundamental and Applied Kinesiology, 46(2), 242-248. https://hrcak.srce.hr/131928

Eom, H. J., \& Schutz, R. W. (1992). Statistical analyses of volleyball team performance. Research Quarterly for Exercise and Sport, 63(1), 11-18. https://doi.org/10.1080/02701367.1992.10607551

Marcelino, R. O., Sampaio, J. E., \& Mesquita, I. M. (2012). Attack and serve performances according to the match period and quality of opposition in elite volleyball matches. The Journal of Strength \& Conditioning Research, 26(12), 3385-3391. https://doi.org/10.1519/jsc.0b013e3182474269

Nicu, A. (Coord.). (2002). Enciclopedia educației fizice și sportului din România [Encyclopaedia of physical education and sport in Romania] (Vol. 4). București: Aramis.

Palao, J. M., Santos, J. A., \& Ureña, A. (2004). Effect of team level on skill performance in volleyball. International Journal of Performance Analysis in Sport, 4(2), 50-60. https://doi.org/10.1080/24748668.2004.11868304

Quiroga, M. E., García-Manso, J. M., Rodríguez-Ruiz, D., Sarmiento, S., De Saa, Y., \& Perla Moreno, M. (2010). Relation between in-game role and service characteristics in elite women's volleyball. Journal of Strength and Conditioning Research, 24(9), 2316-2321. https://doi.org/10.1519/jsc.0b013e3181e3812e

Rabaz, F. C., Castuera, R. J., Arias, A. G., Domíguez, A. M., \& Arroyo, M. P. M. (2013). Relationship between performance in game actions and the match result. A study in volleyball training stages. Journal of Human Sport and Exercise, 8(3), S651-S659. http://dx.doi.org/10.4100/jhse.2013.8.Proc3.11 
Sampaio, J., Ibáñez Godoy, S., \& Feu, S. (2004). Discriminative power of basketball gamerelated statistics by level of competition and sex. Perceptual and Motor Skills, 99(3 Pt 2), 1231-1238. https://doi.org/10.2466/pms.99.3f.1231-1238

Selinger, A., \& Ackermann-Blount, J. (1986). Arie Selinger's power volleyball. New York: St. Martin Press.

Silva, M., Lacerda, D., \& João, P. V. (2014). Game-related volleyball skills that influence victory. Journal of human kinetics, 41(1), 173-179. https://dx.doi.org/10.2478\%2Fhukin-2014-0045

Silva, M., Marcelino, R., Lacerda, D., \& João, P. V. (2016). Match analysis in volleyball: A systematic review. Montenegrin Journal of Sports Science and Medicine, 5(1), 35-46. http://www.mjssm.me/clanci/MJSSM_March_2016_Silva.pdf

Silva, M., Sattler, T., Lacerda, D., \& João, P. V. (2016). Match analysis according to the performance of team rotations in volleyball. International Journal of Performance Analysis in Sport, 16(3), 1076-1086. https://doi.org/10.1080/24748668.2016.11868949

Stone, J. (2002). Digging and ball control. In D. Shondell \& C. Reynaud (Eds.), The volleyball coaching bible (Chapter 17, pp. 163-176). Champaign, IL: Human Kinetics.

Valladares, N., García-Tormo, J. V., \& João, P. V. (2016). Analysis of variables affecting performance in senior female volleyball World Championship 2014. International Journal of Performance Analysis in Sport, 16(1), 401-410. https://doi.org/10.1080/24748668.2016.11868895

Voinea, N. L., \& Rață, G. (2019). Competitive volleyball action efficiency depending on the opponents' level. The European Proceedings of Social \& Behavioural Sciences, LXVII, 982988. https://doi.org/10.15405/epsbs.2019.08.03.118

Voinea, N., Rață, G., \& Grapă, F. (2018). Competitive volleyball action efficiency depending on the competition's location. Gymnasium - Scientific Journal of Education, Sports and Health, XIX(2), 109-119. DOI: 10.29081/gsjesh.2018.19.2.10 